\title{
RESEARCH
}

Open Access

\section{Loss of Tmem106b is unable to ameliorate frontotemporal dementia-like phenotypes in an AAV mouse model of C9ORF72-repeat induced toxicity}

Alexandra M. Nicholson ${ }^{1 \dagger}$, Xiaolai Zhou ${ }^{1 \dagger}$, Ralph B. Perkerson ${ }^{1}$, Tammee M. Parsons ${ }^{1}$, Jeannie Chew ${ }^{1}$, Mieu Brooks ${ }^{1}$, Mariely DeJesus-Hernandez', NiCole A. Finch ${ }^{1}$, Billie J. Matchett ${ }^{1}$, Aishe Kurti ${ }^{1}$, Karen R. Jansen-West ${ }^{1}$, Emilie Perkerson', Lillian Daughrity', Monica Castanedes-Casey', Linda Rousseau', Virginia Phillips' ${ }^{1}$ Fenghua Hu², Tania F. Gendron', Melissa E. Murray', Dennis W. Dickson', John D. Fryer', Leonard Petrucelli ${ }^{1}$ and Rosa Rademakers ${ }^{1 *}$ (i)

\begin{abstract}
Loss-of-function mutations in progranulin (GRN) and a non-coding (GGGGCC) ${ }_{n}$ hexanucleotide repeat expansions in C9ORF72 are the two most common genetic causes of frontotemporal lobar degeneration with aggregates of TAR DNA binding protein 43 (FTLD-TDP). TMEM106B encodes a type II transmembrane protein with unknown function. Genetic variants in TMEM106B associated with reduced TMEM106B levels have been identified as disease modifiers in individuals with GRN mutations and C9ORF72 expansions. Recently, loss of Tmem106b has been reported to protect the FTLD-like phenotypes in Grn-/- mice. Here, we generated Tmem 1066-/- mice and examined whether loss of Tmem106b could rescue FTLD-like phenotypes in an AAV mouse model of C9ORF72-repeat induced toxicity. Our results showed that neither partial nor complete loss of Tmem106b was able to rescue behavioral deficits induced by the expression of (GGGGCC) 66 repeats (66R). Loss of Tmem106b also failed to ameliorate 66R-induced RNA foci, dipeptide repeat protein formation and PTDP-43 pathological burden. We further found that complete loss of Tmem106b increased astrogliosis, even in the absence of 66R, and failed to rescue 66R-induced neuronal cell loss, whereas partial loss of Tmem106b significantly rescued the neuronal cell loss but not neuroinflammation induced by 66R. Finally, we showed that overexpression of 66R did not alter expression of Tmem106b and other lysosomal genes in vivo, and subsequent analyses in vitro found that transiently knocking down C9ORF72, but not overexpression of 66R, significantly increased TMEM106B and other lysosomal proteins. In summary, reducing Tmem106b levels failed to rescue FTLD-like phenotypes in a mouse model mimicking the toxic gain-of-functions associated with overexpression of 66R. Combined with the observation that loss of C9ORF72 and not 66R overexpression was associated with increased levels of TMEM106B, this work suggests that the protective TMEM106B haplotype may exert its effect in expansion carriers by counteracting lysosomal dysfunction resulting from a loss of C9ORF72.
\end{abstract}

\footnotetext{
* Correspondence: rademakers.rosa@mayo.edu

${ }^{+}$Alexandra M. Nicholson and Xiaolai Zhou contributed equally to this work.

'Department of Neuroscience, Mayo Clinic Jacksonville, 4500 San Pablo Road, Jacksonville, FL 32224, USA

Full list of author information is available at the end of the article
}

(c) The Author(s). 2018 Open Access This article is distributed under the terms of the Creative Commons Attribution 4.0 International License (http://creativecommons.org/licenses/by/4.0/), which permits unrestricted use, distribution, and reproduction in any medium, provided you give appropriate credit to the original author(s) and the source, provide a link to the Creative Commons license, and indicate if changes were made. The Creative Commons Public Domain Dedication waiver (http://creativecommons.org/publicdomain/zero/1.0/) applies to the data made available in this article, unless otherwise stated. 


\section{Introduction}

Frontotemporal dementia (FTD) is a devastating neurodegenerative disorder with initial symptoms occurring in the fifth or sixth decade of life. While most cases of FTD develop sporadically, 30-50\% of FTD cases report a family history $[23,43,44,47,61]$, in support of a strong genetic component to the disease. Two of the most common gene mutations found to cause FTD reside in the progranulin $(G R N)$ and chromosome 9 open reading frame 72 (C9ORF72) genes [6, 14, 17, 45]. Causative GRN mutations leading to FTD include heterozygous missense, nonsense, or frameshift changes that most often lead to nonsense-mediated decay of the mutant mRNA and an associated loss of progranulin protein (PGRN). Individuals with GRN mutations invariably present with aggregates of the TAR DNA binding protein 43 (TDP-43) in affected brain regions, and are thus pathologically classified as FTLD-TDP $[4,36]$. In C9ORF72, a non-coding (GGGGCC) $\mathrm{n}$ hexanucleotide repeat expansion is responsible for up to $25 \%$ of familial and $5 \%$ of sporadic FTD patients $[17,45]$. Extensive research has shown that the presence of these expanded repeats leads to multiple pathogenic mechanisms, including a loss of C9ORF72 mRNA expression and toxic gain-of-functions resulting from nuclear RNA aggregates and dipeptide repeats proteins [5, 17, 33, 34, 45]. FTD patients with C9ORF72 expansions also present with FTLD-TDP at autopsy, suggesting a potentially convergent disease mechanism between GRN- and C9ORF72-induced pathogenesis.

In 2010, a genome-wide association study (GWAS) identified genetic variants at the transmembrane protein $106 \mathrm{~B}$ (TMEM106B) gene locus as the first genetic modifiers of FTLD-TDP [59]. TMEM106B variants were found to be a modifier of disease risk in FTLD-TDP patients of unknown cause, and a modifier of disease penetrance and presentation in GRN mutation and C9ORF72 expansion carriers $[13,19,21,30,37,58-60]$. Specifically, in C9ORF72 carriers, we showed that individuals who were also homozygous for the minor alleles at the associated TMEM106B variants were significantly protected from developing FTD but not amyotrophic lateral sclerosis (ALS) symptoms [18, 58], another common phenotypic presentation in C9ORF72 expansion carriers.

The TMEM106B protein resides in lysosomal compartments where it might be involved in lysosomal function and/or trafficking [7, 11, 29, 50, 53]. Overexpression of TMEM106B results in abnormal lysosomal size, number, and acidification [7, 11]. Interestingly, recent studies determined that the protective TMEM106B variants are associated with reduced levels of TMEM106B [20, 37, 59], suggesting that lowering TMEM106B might be therapeutic in the context of FTD. In fact, lysosomal deficits observed in Grn knockout mice were recently rescued by loss of Tmem106b expression [26]. In this study, we aimed to examine whether loss of Tmem106b expression was able to rescue FTD-like behavioral and pathological features observed in an adeno-associated virus (AAV)-based mouse model mimicking the toxic gain-of-functions associated with overexpression of (GGGGCC) 66 repeats.

\section{Methods}

\section{Tmem106b knockout mice}

Tmem106b knockout mice were generated at the Knockout Mouse Project (KOMP) Repository at the University of California, Davis using the PGS00041_A_C06 targeting vector and blastocyst injection of the targeted embryonic stem cell clone EPD0047_1_E02 generated from C57BL/6 N mice. This knock-in first strategy results in the insertion of a lac $Z$ gene trap between the first two coding exons (exons 3 and 4 ) of the mouse Tmem106b gene. Cryopreserved sperm were purchased and used to inseminate oocytes obtained from 3-week-old C57BL/6N female mice (Harlan, Indianapolis, IN). Zygotes that reached the 2-cell-stage $24 \mathrm{~h}$ post insemination were surgically transferred into foster dams (Harlan). DNA obtained from subsequent pups was screened by multiplex polymerase chain reaction (PCR) for the presence of the NEO cassette before breeding as a colony founder (CSD-Tmem106b-F: 5'-TTCTCTCCATGTGC TGCATTATGAGC-3'; CSD-Neo-F: 5'-GGGATCTCATG CTGGAGTTCTTCG-3'; CDS-Tmem106b-ttR: 5'-ACGTG CTTCTCTCATCTACAGTTTTCC-3'). A Tmem106b+/$\mathrm{x}$ Tmem106+/- breeding scheme was used to generate Tmem106b +/+, +/-, and -/- mice for the experiments. Both male and female mice of each Tmem106b genotype were used for all the experiments. All animal studies were approved by the Mayo Clinic Institutional Animal Care and Use Committee.

\section{Genotyping}

Genomic DNA (gDNA) was extracted and PCR-amplified using the Phire Tissue Direct Master Mix kit (Thermo Scientific Inc., Waltham, MA) per the manufacturer's instructions. Briefly, mouse hair follicles were digested in Dilution Buffer supplemented with DNARelease Additive for $2 \mathrm{~min}$ at room temperature, followed by 2 min incubation at $95{ }^{\circ} \mathrm{C}$. Samples were briefly centrifuged and $1 \mu \mathrm{l}$ of supernatant containing the gDNA was used for each PCR reaction. Tmem106b gene products were amplified using a multiplex PCR approach containing $0.8 \mu \mathrm{M}$ of each forward primer (CSD-Tmem106b-F and CSD-Neo-F), $0.8 \mu \mathrm{M}$ of reverse primer (CDS-Tmem106b-ttR), and Phire Tissue Direct PCR Master Mix (Thermo Scientific).

\section{Viral production and injections}

Viruses were generated as previously described [12, 22, 54]. Briefly, (GGGGCC) 2 (2R) or (GGGGCC) 66 (66R) C9ORF72 repeats were cloned into the pAM/CBA-pl-WPRE-BGH 
vector containing inverted repeats of serotype 2 . AAV vectors containing the repeats were packaged into the serotype 9 type capsid by co-transfection with helper plasmids into HEK293T cells. The cells were harvested and lysed 2 days post transfection in the presence of $0.5 \%$ sodium deoxycholate and $50 \mathrm{U} / \mathrm{ml}$ Benzonase (Sigma Aldrich, St. Louis, $\mathrm{MO})$ by freeze thawing. The virus was isolated using a discontinuous iodixanol gradient, and qPCR was used to determine the genomic titer of each virus. $2 \mathrm{R}$ and $66 \mathrm{R}$ AAV were diluted to $1_{\mathrm{E}} 13$ genomes $/ \mathrm{ml}$ in sterile phosphate-buffered saline (PBS) before injection. Mouse pups underwent intracerebroventricular injections with virus at postnatal day 0 (P0) $[10,12,25]$. Pups were cryoanesthetized on ice and their heads were wiped with a sterile alcohol pad. Two microliters of virus were manually injected into each cerebral ventricle using a 32 gauge needle attached to a $10 \mu \mathrm{l}$ syringe (Hamilton Company, Reno, NV). After injection, pups were warmed on a heating pad and placed back with the dam. All litters were injected within an 8-day timeframe and mice were aged to 12 months before assessing behavior and pathological manifestations. Small subsets of mice were harvested at 3 months of age to study Tmem106b expression and validate the model.

\section{Open field test}

Mice were placed in a square, Perspex box $(40 \times 40 \times 30 \mathrm{~cm}$, LxWxH) containing side-mounted photobeams placed $7.6 \mathrm{~cm}$ above the bottom of the box. Mice were allowed to move freely for $15 \mathrm{~min}$, during which locomotor activity and anxiety measurements were taken. The Perspex box was illuminated by a light suspended over the chamber, and an overhead camera and AnyMaze software (Wood Dale, IL) were used to monitor mouse movement, such as time mobile, total distance traveled, and distance traveled in the outer and center zones. Mouse rearing was recorded by breaking of the photobeams.

\section{Conditional fear testing}

Each mouse was placed in a sound-reducing chamber containing a grid floor capable of inducing an electric shock. An overhead camera and FreezeFrame software (Actimetrics, Wilmette, IL) were used to measure freezing. The mice were left undisturbed for the first $2 \mathrm{~min}$ of the test and baseline freezing was recorded. An $80-\mathrm{dB}$ white noise was then administered for $30 \mathrm{~s}$ (conditioned stimulus; CS). During the last $2 \mathrm{~s}$ of the CS, a $0.5 \mathrm{~mA}$ foot shock was administered to the mouse (unconditioned stimulus; US). After $1 \mathrm{~min}$, a second CS-US pair was given to the mouse and the mouse was removed from the chamber and placed in his/her home cage $30 \mathrm{~s}$ later. Each mouse was returned to the testing chamber $24 \mathrm{~h}$ later and freezing behavior was recorded for $5 \mathrm{~min}$ (context test). All mice were returned to their home cages and transferred to a different room with reduced light for at least $1 \mathrm{~h}$. Contextual cues were changed by altering the environment, shape, and smell of the testing chamber, as well as by covering the chamber floor with opaque plastic. Each mouse was placed back into the test chamber and the auditory stimulus was presented. Freezing was recorded for 3 min (cued test). For both the context and cued tests, baseline freezing time was subtracted from the freezing time obtained during each test.

\section{Social interaction test}

Each mouse was placed into a rectangular box subdivided into three chambers. Two larger chambers measured $17 \times 40 \mathrm{~cm}$ with a smaller chamber of $5 \times 40$ $\mathrm{cm}$ in the middle. The three chambers were connected by an $8 \times 5 \mathrm{~cm}$ opening to allow the mouse free access to all chambers. Two empty, inverted wire-mesh cylinders were placed in opposite corners of each large chamber. In the first trial, mice were placed in the box and allowed to explore the apparatus freely for $4 \mathrm{~min}$ before being placed into a temporary holding cage. Next, a probe mouse (matched for sex/strain) was placed in one of the cylinders for $3 \mathrm{~min}$ prior to reintroduction of the test mouse. An overhead camera and Anymaze software (Stoelting Co.) were used to monitor mouse interactions for $10 \mathrm{~min}$. The time each test mouse spent in the area containing the cylinder with the probe mouse was used to determine sociability.

\section{Tissue harvests}

Mice were subjected to carbon dioxide narcosis and body weight was obtained (SCALTEC SBA 53 scale; Denver Instrument, Bohemia, NY) before decapitation. Mouse blood was collected in tubes containing $1.6 \mathrm{mg} /$ $\mathrm{ml}$ EDTA and placed on ice. Blood samples were centrifuged at $4{ }^{\circ} \mathrm{C}$ for $10 \mathrm{~min}$ at $5000 \mathrm{rpm}$, after which the resulting plasma supernatant was transferred to a new tube for storage at $-80{ }^{\circ} \mathrm{C}$ until use. The brain was removed and its weight recorded (SCALTEC SBC 32 scale; Denver Instrument) before separating the hemispheres. Whole mouse brains from uninjected mice were either immediately dehydrated and flash frozen in a beaker of isopentane on dry ice or fixed for $24 \mathrm{~h}$ at $4{ }^{\circ} \mathrm{C}$ in $4 \%$ paraformaldehyde (PFA) prepared in PBS. For all injected mice, the left hemisphere was fixed in PFA at $4{ }^{\circ} \mathrm{C}$ for $48 \mathrm{~h}$. The right hemisphere was immediately dehydrated and flash frozen in a beaker of isopentane on dry ice. Following PFA fixation, brain tissues were washed and stored in PBS at $4{ }^{\circ} \mathrm{C}$ until being embedded in paraffin wax.

\section{Cell culture and transfection}

HeLa and U251 cells (ATCC, Manassas, VA) were cultured and maintained in Eagle's Minimum Essential Medium (EMEM) supplemented with 10\% FBS and 1\% 
penicillin/streptavidin. All cell lines were maintained at $37{ }^{\circ} \mathrm{C}, 5 \% \mathrm{CO}_{2}$. For overexpression studies, cells were transiently transfected with pAAV C9ORF72 $2 \mathrm{R}$ or pAAV C9ORF72 66R using Lipofectamine 2000 (Invitrogen, Carlsbad, CA) by mixing DNAs with the transfection reagent in OptiMEM (Life Technologies, Carlsbad, CA, USA) according to the manufacturer's protocol. For the siRNA knockdown experiments, HeLa and U251 cells were transfected with $20 \mathrm{nM}$ of either negative control siRNA or siRNAs against human C9ORF72 using Lipofectamine RNAiMAX Reagent (Life Technologies) according the manufacturer's protocol. The control siRNA (5'-UGGUUUACAUGUCGACUAA-3', D-001210-05) and human C9ORF72 siRNA (5'-CAUAGAGUGUGUGUUG AUA-3', J-013341-11) were purchased from Dharmacon (Lafayette, CO). Cells were harvested for protein extraction 48 and $72 \mathrm{~h}$ post transfection for overexpression and siRNA experiments, respectively.

\section{RNA and protein extraction}

Frozen brain tissue was homogenized by sonication in tris-buffered saline (TBS) containing $2 \mathrm{X}$ protease and phosphatase inhibitors (Thermo Scientific). RNA was isolated from $75 \mu \mathrm{l}$ of brain homogenate using the RNeasy Plus Mini Kit (Qiagen, \#74136) according to the manufacturer's instructions. Briefly, brain tissue was lysed using Buffer RLT containing $\beta$-ME, and then passed through the gDNA Eliminator column to remove DNA. The RNA containing flow-through was precipitated by $70 \%$ ethanol and passed through an RNeasy pink spin column. RNA was eluted from the column with RNase-free water. Protein was also isolated from $75 \mu \mathrm{l}$ of brain homogenate by adding and equivalent volume of 2X Radioimmunoprecipitation Assay (RIPA) buffer (Boston BioProducts, Ashland, MA). For cell culture experiments, media was removed and RIPA buffer was added directly to PBS-rinsed cell culture wells. All RIPA samples were incubated on ice and centrifuged at $4{ }^{\circ} \mathrm{C}$ for $5 \mathrm{~min}$ at $6000 \mathrm{rpm}$ to clear debris. Protein content in brain samples was measured in the supernatant using the bicinchoninic acid (BCA) assay (Thermo Fisher Scientific).

\section{Quantitative PCR}

Brain RNA was reverse transcribed using the Superscript III complimentary DNA (cDNA) synthesis kit, random hexamers (Life Technologies), and an equal ratio of random hexamers and Oligo dT primers (Thermo Fisher Scientific). Real-time quantitative PCRs (qPCRs) were conducted using TaqMan gene expression assays and the QuantStudio 7 Flex Real-Time PCR System (Applied Biosystems, Foster City, CA). All probes were purchased from Life Technologies: Tmem106a (Mm01246747_m1), Tmem106b (Mm005 10952_m1), Tmem106c (Mm01303550_m1), Iba1 (Aif1;
Mm00479862_g1), Gfap (Mm01253033_m1), and Gapdh (Mm99999915_g1).

\section{Western blotting}

Protein samples were mixed with an equivalent volume of 2X Novex sample buffer (Life Technologies) supplemented to $5 \% \beta$-mercaptoethanol. Proteins were denatured by incubating at room temperature for $30 \mathrm{~min}$ or by heating at $95{ }^{\circ} \mathrm{C}$ for $1-5 \mathrm{~min}$ before loading into SDS-polyacrylamide gels (Life Technologies). Proteins were transferred to Immobilon membranes (Millipore, Billerica, MA) and immunoblotted with the primary antibody at $4{ }^{\circ} \mathrm{C}$ overnight. The next day, blots were incubated with an HRP-conjugated secondary antibody (Promega, Madison, WI) and bands were detected by enhanced chemiluminescence using Western Lightning Plus-ECL reagents (Perkin Elmer, Waltham, MA). Primary antibodies included: rabbit anti-Tmem106b from Bethyl Laboratories (A303-439A), rabbit anti-Tmem106b generously shared and derived in the lab of Dr. Fenghua $\mathrm{Hu}$, sheep anti-mouse progranulin (AF2557; R\&D systems, Minneapolis, MN), goat anti-human progranulin (AF2420; R\&D systems, Minneapolis, MN), mouse anti-Gapdh (H86504M; Meridian Life Sciences, Cincinnati, $\mathrm{OH}$ ), mouse anti-Lamp1 (sc-20,011; Santa Cruz Biotechnology, Dallas, TX), rabbit anti-C9ORF72 (ABN1645; Millipore), mouse anti-HA (clone12CA5; \#11583816001; Roche, Indianapolis, IN), and goat anti-Cathepsin-D (clone C-20; sc-6486; Santa Cruz Biotechnology, Dallas, TX). Bands of Western blots were quantified using Image $\mathrm{J}$ (NIH, Bethesda, MD).

\section{Poly(GP) immunoassay}

Poly(GP) protein levels were measured in $10 \mu \mathrm{g}$ of protein in duplicate from mouse brain lysates using a sandwich immunoassay utilizing MesoScale Discovery (MSD) technology as previously described [12, 22]. Serial dilutions of recombinant $(\mathrm{GP})_{8}$ were used as a standard curve. Response values were measured using the MSD QUICKPLEX SQ120 and are defined as the intensity of emitted light upon electrochemical stimulation. Each sample's response value was corrected for background response detected in 2R-injected mouse samples prior to interpolation of poly $(\mathrm{GP})$ levels using the standard curve.

\section{Immunohistochemistry and digital analysis}

Paraffin-embedded mouse brain tissues were cut on a sagittal plane at a thickness of $5 \mu \mathrm{m}$, deparaffinized with xylene, and rehydrated in a series of ethanol washes. For slides stained with mouse anti-NeuN (ABN78; Millipore) or rabbit anti-pTdp-43 (TIP-PTD-P01; pSer409/410; Cosmo Bio USA, Carlsbad, CA), antigen retrieval was performed by steaming slides for $30 \mathrm{~min}$ with distilled 
water before blocking in $0.03 \%$ hydrogen peroxide. Immunostaining of sections was done using a Dako Autostainer and Envision + HRP system (Dako, Carpintaria, CA) per the manufacturer's instructions. For slides stained with rabbit anti-pTdp-43 (pSer409/410; gift from Dr. Leonard Petrucelli), antigen retrieval was performed by steaming slides for $30 \mathrm{~min}$ in sodium citrate buffer $(10 \mathrm{mM}$ sodium citrate, pH 6.0 with $0.05 \%$ Tween-20) and immunostaining was performed using the VectaStain Elite ABC HRP kit (Vector Laboratories, Burlingame, CA) per the manufacturer's instructions. All slides were counterstained with hematoxylin, washed in a series of alcohols, and dehydrated in xylene. Glass coverslips were mounted using Cytoseal XYL (Thermo Scientific) and were left to set at room temperature for $48 \mathrm{~h}$ before scanning with an Aperio ScanScope AT2 Slide Scanner (Leica Biosystems, Buffalo Grove, IL). ImageScope software (v12.1.0.5029; Leica) was used to annotate the cerebral cortex and motor cortex of NeuN- and pTdp-43-stained slides. A custom-designed algorithm was applied to detect the number of pTdp-43-positive nuclei per area $\left(\mathrm{mm}^{2}\right)$ [12] when labeled with the Cosmo antibody. The total number of pTdp-43-positive cells were counted manually for slides stained with the pTdp-43 antibody provided by Dr. Petrucelli.

\section{RNA fluorescence in situ hybridization (FISH)}

RNA FISH was performed in fixed mouse brain tissue as done previously $[12,28]$. Briefly, paraffin embedded brain sections were deparaffinized in xylene and rehydrated in a series of ethanol solutions. Sections were permeabilized with ice-cold $2 \%$ acetone in PBS prepared in DEPC-treated water for $5 \mathrm{~min}$. Sections were then washed twice with DEPC-treated water and dehydrated in a series of ethanol solutions before incubating $30 \mathrm{~min}$ at $66{ }^{\circ} \mathrm{C}$ in pre-hybridization buffer [50\% formamide/2X SSC (MIDSCI, Valley Park, MO), 10\% dextran sulfate (Millipore), $2 \times$ saline-sodium citrate buffer, $50 \mathrm{mM}$ sodium phosphate buffer, $\mathrm{pH}$ 7.0]. A fluorescently labeled locked nucleic acid (LNA) probe (5'TYE563/CCCC GGCCCCGGCCCC-3', Exiqon, Inc.; batch number 612968) was diluted to $40 \mathrm{nM}$ in in hybridization buffer (10\% dextran sulfate, $50 \%$ formamide, $20 \mathrm{ng} / \mu \mathrm{l} \mathrm{BSA}$, $25 \mathrm{mM}$ tRNA, $25 \mathrm{nM}$ EDTA, 2X SSC, $25 \mathrm{mM}$ sodium phosphate buffer) and denatured at $80{ }^{\circ} \mathrm{C}$ for $5 \mathrm{~min}$ before hybridizing to the tissue for $24 \mathrm{~h}$ at $66{ }^{\circ} \mathrm{C}$ in a dark, humid chamber. Sections were subsequently washed once with $2 \mathrm{X}$ SSC $(0.1 \%$ Tween-20) at room temperature for $5 \mathrm{~min}$ and washed twice with pre-warmed $0.2 \mathrm{X} \mathrm{SSC}$ at $55{ }^{\circ} \mathrm{C}$ for $10 \mathrm{~min}$ in the dark. Slides were mounted with Vectashield mounting media containing DAPI (Vector Laboratories). Cortical images of RNA foci were obtained using a Zeiss Axio Imager Z1 fluorescent microscope (Zeiss, Oberkochen, Germany) under $63 \times$ magnification and the number of cells containing RNA foci were quantified.

\section{Statistical analyses}

For experiments in which only two groups were compared, significance was measured using a Student's t-test. For analyses involving more than two groups, GraphPad Prism 5.04 (GraphPad Software) was utilized to perform a one-way ANOVA or two-way ANOVA followed by the Fisher's LSD post hoc test.

\section{Results}

\section{Generation and validation of Tmem106b knockout mice}

Tmem106b knockout alleles were generated by insertion of a lacZ gene trap in the intronic region between the first two coding exons, exons 3 and 4 . The inserted gene is transcribed by the endogenous Tmem106 $b$ promoter along with the upstream exons and leads to a premature termination of transcription (Fig. 1a). Inheritance of this targeted gene disruption was confirmed by PCR amplification of the genomic DNA isolated from Tmem106b $+/+,+/-$, and $-/-$ mice (Fig. 1b). qPCR analysis in 3, 8 and 15 months old mice further confirmed the loss of Tmem106b mRNA transcripts with mice heterozygous for the knockout allele showing approximately 50\% loss as compared to age matched wild-type mice and a near complete loss of Tmem106b mRNA in Tmem106b -/mice (Fig. 1c, Additional file 1: Figure S1). Loss of Tmem106 $b$ transcripts did not alter the expression of other Tmem106 family members, Tmem106a and Tmem106c (Additional file 1: Figure S2). Western blotting of wild-type mouse brain lysates with a Tmem106b antibody (Bethyl Laboratories) revealed a robust Tmem106b-immunoreactive band at the predicted $43 \mathrm{kDa}$ molecular weight. This band's intensity was reduced approximately $50 \%$ in samples from Tmem106b +/- mice and was undetectable in Tmem106b -/- brain tissue (Fig. 1d, e). Of note, using an in-house developed Tmem106b antibody against the intracellular domain of TMEM106B (residues 1-96) [7], small molecular weight bands could also be detected upon long exposure in Tmem106b +/- and Tmem106b -/- mice. These additional bands likely correspond to Tmem106b-lacZ truncated fragments which are expected in mouse models created by the lacZ gene trap approach [9] (Additional file 1: Figure S3).

Tmem106b loss does not reverse abnormal behaviors in mice expressing (GGGGCC) 66 repeat

To determine whether reduced Tmem106b levels might be protective against FTD-like behavioral phenotypes in the AAV-(GGGGCC) 66 mouse model, the newborn Tmem106b +/+, +/-, and -/- mice were injected with either AAV- 66R or AAV-2R (control) and aged to 


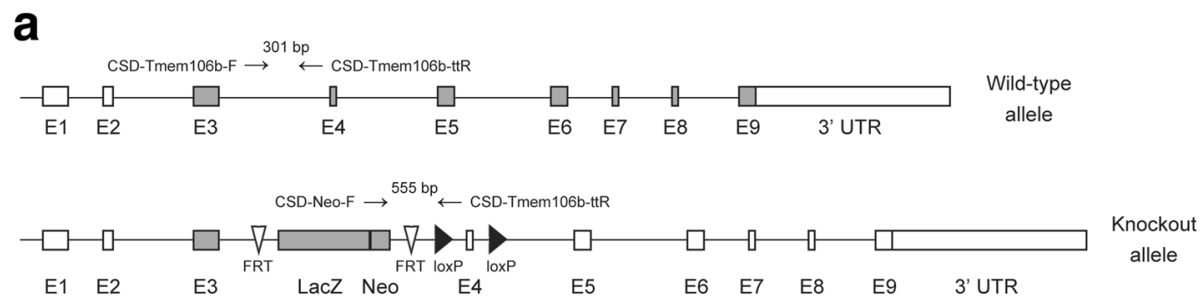

b

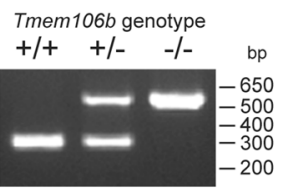

C

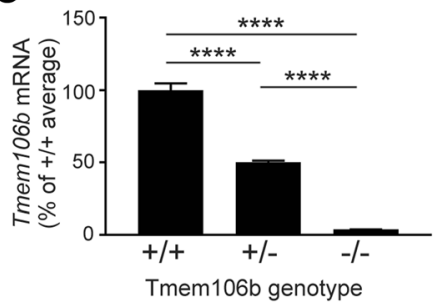

d

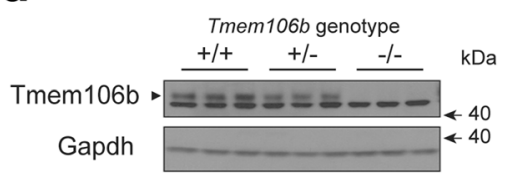

$\mathbf{e}$

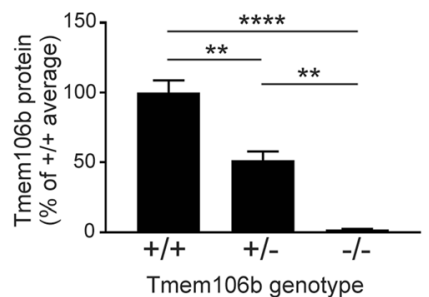

Fig. 1 Generation of mice with targeted Tmem106b gene disruption. a Genomic structure of the wild-type mouse Tmem $106 b$ allele and the gene trap vector used to target the mouse Tmem106b gene. Rectangular boxes represent exons that are shaded in gray or white to denote coding and non-coding exons, respectively. White arrowheads signify Flp recombination target (FRT) sites and black arrowheads represent loci of crossover in P1 (LoxP) sites. Genotyping primer binding sites are labeled and denoted with black arrows above each genomic structure. $\mathbf{b}$ PCR analysis of DNA obtained from the hair follicles of Tmem106b wild-type (+/+), heterozygous (+/-), or knockout (-/-) mice using the primers depicted in panel a. c Quantitative PCR analysis measuring Tmem106b mRNA levels in Tmem 106b +/,$++/-$, and $-/-$ mouse brain $(n=4$ per genotype) at 3 months of age. The graph represents the mean \pm S.E.M.; ${ }^{* * * *} p<0.0001$ by one-way ANOVA followed by a Fisher's LSD post-hoc test. $\mathbf{d}$ Western blot depicting Tmem106b protein levels (black arrowhead) in 3-month-old Tmem106b +/+, +/-, and -/- mouse brain tissue. Gapdh was used as a loading control. e Quantification of Tmem106b protein levels in Tmem106b +/+, +/-, and -/- mouse brain at 3 months of age ( $n=3$ per genotype)

12 months of age. 66R virus injection did not affect the overall activity (data not shown) or body weight of the mice; except for a reduced body weight in female Tmem106 $b+/+$ mice injected with $66 \mathrm{R}$ as compared to $2 \mathrm{R}$ which could be contributed to the small number of mice in this sub-group (Additional file 1: Figure S4). In line with the original study describing this model [12], injection of the $66 \mathrm{R}$ virus into wild-type mice induced significant behavioral deficits, including anxiety and reduced sociability as compared to $2 \mathrm{R}$-injected wild-type mice ( $p=0.019$ by Student's t-test for all wild-type $2 \mathrm{R}$ vs. $66 \mathrm{R}$ analyses; Fig. 2a-e). However, neither partial nor complete reduction of Tmem106b altered the anxiety phenotype observed in 66R-injected wild-type mice as determined by the open field assay (Fig. 2a, b) or fear conditioning tests (Fig. 2c, d). Also, the reduced mouse sociability observed in 66R-injected mice could not be rescued in mice with partial or complete loss of Tmem106b (Fig. 2e). Since the amount of 66R viral expression could affect the presence and/or severity of these phenotypes, we performed qPCR analysis on all 66R-injected mouse brains, which showed no significant difference in 66R mRNA expression among Tmem106b +/+, +/-, and -/- mice (Fig. 2f).

\section{(GGGGCC) 66 repeat-induced neuropathology is not rescued by lowering Tmem 106b expression}

We next determined whether lowering Tmem106b expression was able to ameliorate key hallmarks of neurodegeneration, such as neuroinflammation and neuronal loss, previously reported in the AAV-66R mouse model [12]. At 12 months of age, wild-type mice injected with $66 \mathrm{R}$ virus showed significantly increased levels of Ibal and Gfap mRNA transcripts as compared to 2R-injected animals, indicating pronounced neuroinflammation ( $p=0.024$ by Student's t-test for both analyses; Fig. 3a, b). However, neither partial nor complete reduction of Tmem106b levels was able to rescue these changes; in fact, 66R-injected Tmem106b -/- mice had significantly higher Gfap mRNA levels than 66R-injected wild-type mice (Fig. 3b). Follow-up analysis in uninjected Tmem106b +/+, +/-, and -/- mice further 


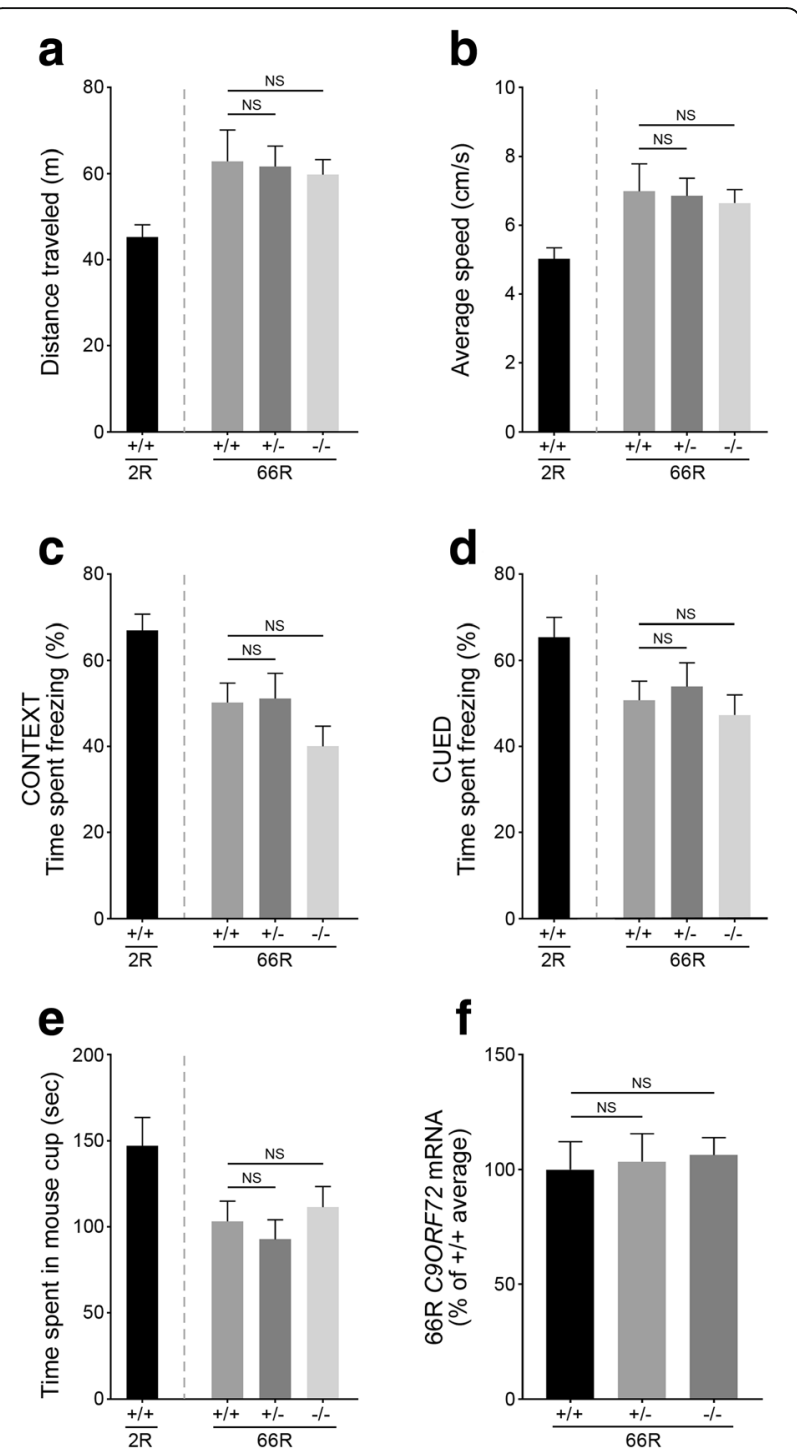

Fig. 2 (GGGGCC) $)_{66}$ repeat-induced behavioral deficits are unchanged by Tmem 106b reduction. a Quantification of the average distance traveled obtained during the open field assay for 66R-injected Tmem106b $+/+,+/-,-/-$ mice at 12 months of age. Wild-type mice of the same age that had been injected with 2R C9ORF72 were used as a control. $\mathbf{b}$ Quantification of the average speed traveled during the open field assay for mice as described in (a). c-d Quantification of the time each mouse spent freezing during the contextual (c) and cued (d) fear conditioning tests. e Quantification of the time each mouse spent exploring the mouse-containing cup during the social interaction test ( $\mathbf{f}$ qPCR quantification measuring the amount of $66 \mathrm{R}$ mRNA obtained from the brains of 12-month-old 66R-injected Tmem106b +/+, +/-, and -/- mice. Graphs represent the mean \pm S.E.M. Data was analyzed by one-way ANOVA followed by Fisher's LSD post-hoc, and results are shown for 66R-injected Tmem106b $+/-$ and $-/$ - mice as compared to 66R-injected wild-type mice ( $n \geq 12$ for all groups). NS, not significant

showed that full loss of Tmem106b (in the absence of repeat overexpression), is sufficient to induce astrogliosis as determined by a significant increase in Gfap mRNA levels in Tmem106b -/- as compared to Tmem106 +/+ mice (Additional file 1: Figure S5). Gfap mRNA levels in Tmem106b +/- mice were not significantly different from Tmem106b +/+ mice.

We next assessed the effect of Tmem106b reduction on 66R-induced neuronal loss. As expected, 66R-injected Tmem106b +/+ mice portrayed a significantly reduced number of cells immunoreactive for the neuronal marker, NeuN, as compared to 2R-injected mice ( $p=0.016$ by Student's t-test; Fig. 3c). Complete loss of Tmem106b did not modify this phenotype; however, partial reduction of Tmem106b significantly lessened the extent of neuronal loss associated with $66 \mathrm{R}$ injection. In fact, 66R-injected Tmem106b +/- cortical NeuN counts were not significantly different from that of $2 \mathrm{R}$-injected animals ( $p=0.0512$ by Student's t-test; Fig. 3c, Additional file 1: Figure S6). This was not due to the presence of more NeuN-positive cells present in Tmem106b heterozygous mice given that uninjected Tmem106b +/+, +/-, and -/- mice have comparable NeuN counts (Additional file 1: Figure S5).

We next studied two unique pathologies induced by overexpression of the 66R repeat: RNA foci and dipeptide repeat proteins. Parallel to what was previously reported, RNA foci and poly-glycine/proline dipeptides [poly(GP)] were detected at significant levels in 66R-injected wild-type mice and not 2R-injected mice (Fig. 3d-f). We quantified the percentage of cells containing one or more RNA foci in the cortex of 66R-injected Tmem106b +/+, +/-, and -/- mice. As depicted in Fig. 3e, partial or complete reduction of Tmem106b levels did not significantly change the number of RNA foci-containing cells. Similarly, poly(GP) levels in 66R-injected Tmem106b $+/$ - and $-/-$ mice were similar to that of 66R-injected wild-type mice (Fig. 3f).

Finally, we examined the effect of Tmem106b reduction on the formation of intracellular inclusions of phosphorylated Tdp-43 (pTdp-43), a key pathological feature observed both in patients and in mice injected with 66R [12, 17, 45]. We detected intense pTdp-43-positive inclusions in 66R- but not 2R-injected Tmem106b +/+ brains using two different antibodies that recognize Tdp-43 in its phosphorylated form (Fig. 4a, Additional file 1: Figure S7). However, neither partial nor complete loss of Tmem106b significantly changed the number of pTdp-43-positive cells in the cortex or hippocampus (Fig. 4b; Additional file 1: Figure S7).

\section{C9ORF72 loss increases TMEM106B levels unlike (GGGG CC) ${ }_{66}$ overexpression}

To further study the connection between TMEM106B and C9ORF72-related disease mechanisms, we determined Tmem106b protein levels in wild-type mice that had been injected with $66 \mathrm{R}$ or $2 \mathrm{R}$ virus. Tmem $106 \mathrm{~b}$ 

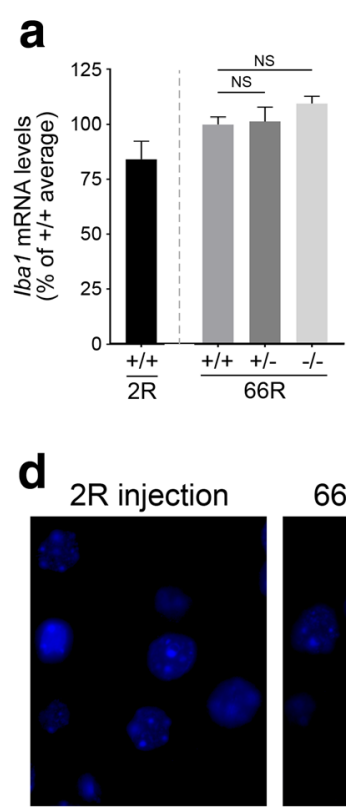

Tmem106b+l+
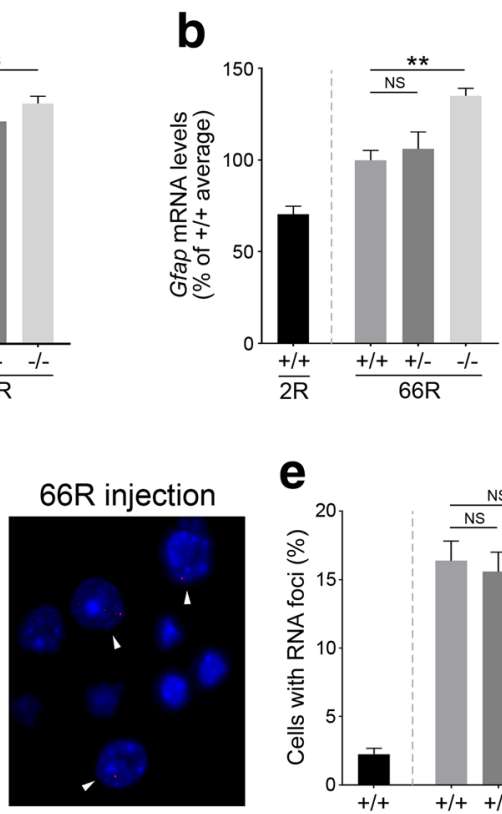

$\Delta$ e

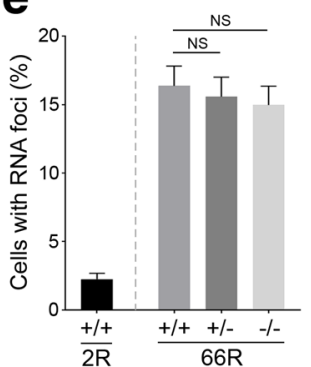

C

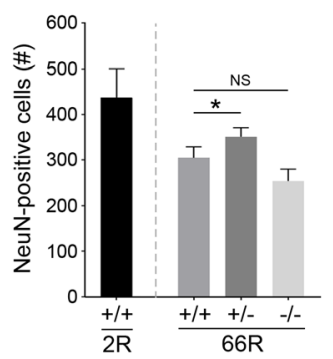

f

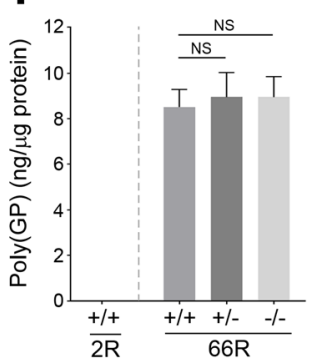

Fig. 3 Assessment of (GGGGCC) ${ }_{66}$-mediated neuropathology in response to changes in Tmem106b levels (a-b) Quantification of Iba1 (a) or Gfap (b) mRNA levels in the cortex of 2R-injected mice, or in 66R-injected Tmem106b +/+, +/-, or -/- mice. c Quantitative analysis of the number of cells immunoreactive for NeuN in the cortex of 2R-injected mice, or in 66R-injected Tmem106b $+/+,+/-$, or $-/-$ mice. $\mathbf{d}$ Image depicting the presence of RNA foci (arrowheads) in the nuclei of cortical cells in wild-type 66R- versus 2R-injected mice. e Quantification of the number of cells with RNA foci in the cortex of wild-type 2R-injected mice, or in 66R-injected Tmem 106b +/+, +/-, or -/- mice. f Quantitative assessment of the presence of poly(GP) peptides detected in the brains of mice injected as described in panel e. Graphs represent the mean \pm S.E.M. Data was analyzed by one-way ANOVA followed by Fisher's LSD post-hoc, and results are shown for 66R-injected Tmem 106b $+/-$ and $-/-$ mice as compared to 66R-injected wild-type mice ( $n=12$ per group). NS, not significant.; ${ }^{*} p<0.05$; ${ }^{* *} p<0.001$

\section{a}

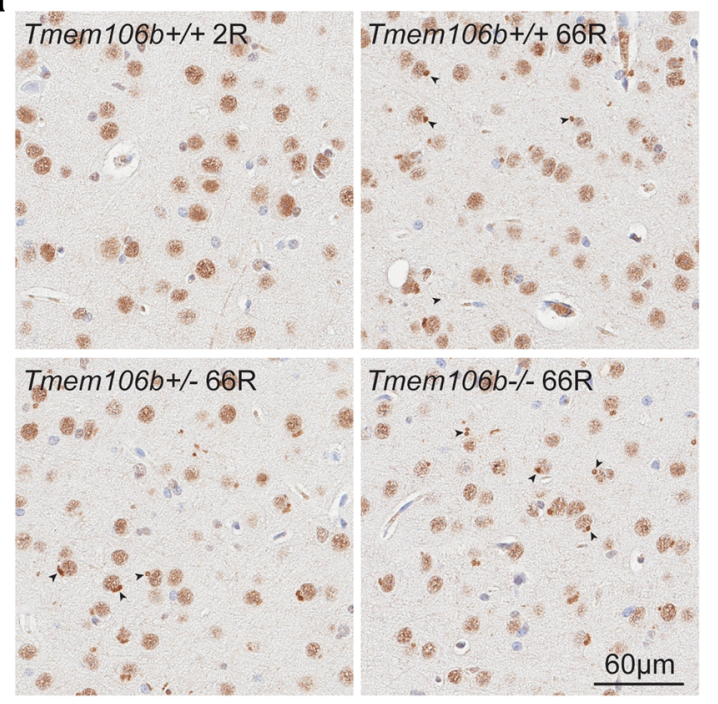

b

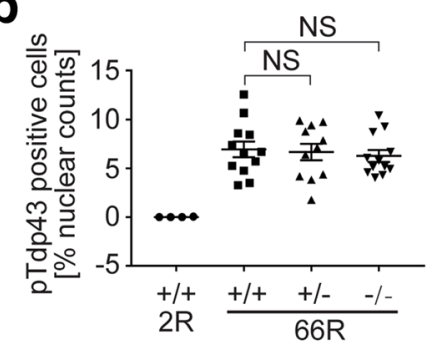

C

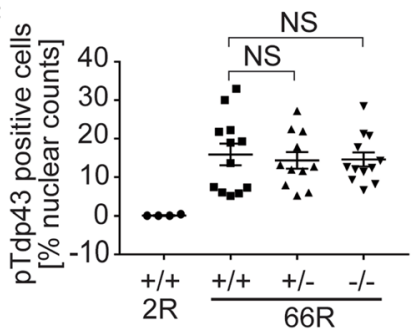

Fig. 4 Tmem106b levels do not affect (GGGGCC) 66 repeat induced pTdp-43 inclusion body formation. a Representative images of pTdp-43 (pS409/410 from Cosmo Bio) staining of motor cortex region of the mouse brains from indicated Tmem 106b genotypes 12 months after 2R and 66R AAV injection. Arrow heads indicate pTdp-43-positive inclusion bodies. $\mathbf{b}$ and $\mathbf{c}$ Quantification of pTdp-43 inclusion body positive cells in different brain regions: cortex (b) or hippocampus (c) from Tmem106b $+/+,+/-$, and $-/-$ mice as compared to WT $2 \mathrm{R}$ injected mice $(n=4)$. Graphs represent the mean \pm S.E.M. Data was analyzed by one-way ANOVA followed by Fisher's LSD post-hoc, and results are shown for 66R-injected Tmem106b +/- and -/- mice as compared to 66R-injected wild-type mice ( $n=12$ per group). NS, not significant 
levels in $66 \mathrm{R}$ injected brains were almost identical to that of $2 \mathrm{R}$ control brains (Fig. 5a, b). The 66R-injected mice also had normal levels of other lysosomal proteins, such as Lamp1, cathepsin D (both pro- and mature forms), and progranulin (Fig. 5a, quantifications not shown). Furthermore, whereas human patients with C9ORF72-related FTD have reduced C9ORF72 levels in addition to the GGGGCC-repeat associated toxicities, endogenous C9ORF72 expression levels were not changed in our 66R overexpression model (Additional file 1: Figure S8). This prompted us to compare the effects of 66R overexpression and C9ORF72 loss on Tmem106b levels in cell culture (techniques validated in Additional file 1: Figure S9). Consistent with the in vivo data, overexpression of 66R in both HeLa and U251 cells failed to change the expression of various lysosomal proteins, including TMEM106B (Fig. 6a-e and Additional file 1: Figure S10). However, knockdown of C9ORF72 significantly increased protein levels of TMEM106B together with other lysosomal resident proteins (Fig. 6f-j and Additional file 1: Figure S10).

\section{Discussion}

Genetic variants in TMEM106B associated with reduced TMEM106B expression have been shown to significantly protect individuals with either GRN mutations or C9ORF72 repeat expansions from the development of FTD symptoms $[13,19,21,30,37,58-60]$. Moreover, depletion of Tmem106b was recently shown to rescue several disease-relevant phenotypes observed in Grn -/mice [26]. This study is the first to determine the impact of Tmem106b reduction on C9ORF72-related disease. Contrary to the relative success in the Grn -/- mouse model, we demonstrate that neither partial nor complete loss of Tmem106b is sufficient to rescue the behavioral changes or neuropathological phenotypes that manifest in an AAV-based mouse model of C9ORF72-associated $(\text { GGGGCC })_{\mathrm{n}}$ expansions. The (GGGGCC) ${ }_{66}$-AAV model was chosen as the model system in this study due to the demonstration of various phenotypes associated with C9ORF72 repeat expansions as early as 6 months of age [12]. At the time this study commenced, only two other characterized C9ORF72-repeat expansion mouse models had been generated. Both of these models were created using a bacterial artificial chromosome (BAC) for the expression of the complete [39] or partial [41] C9ORF72 coding region with incorporated (GGGGCC) repeats of various lengths. These models successfully demonstrated pathologies directly related to the repeat expansion as early as 4-6 months of age, including RNA foci and the generation of dipeptide repeat proteins. However, in contrast to the (GGGGCC) 66 -AAV model, many of the key features of C9ORF72-mediated FTD, especially behavioral deficits, neuroinflammation, neuronal loss, and pTdp-43 pathology, were not observed even in aged mice in these models $[39,41]$. Since TDP-43 pathology is a common denominator of the human disease populations associated with TMEM106B (FTLD-TDP, GRN-carriers, C9ORF72-carriers and AD patients with TDP-43 pathology [38]) the selection of a mouse model with pTdp-43 pathology was considered essential. Importantly however, neither the BAC mice nor our (GGGG $\mathrm{CC})_{66}$-AAV mice recapitulate the loss of C9ORF72 expression consistently observed in human C9ORF72 expansion carriers.

Neuronal loss and neuroinflammation are common features among neurodegenerative disorders. Protective TMEM106B variants were found to associate with increased neuronal gene expression, reduced expression of genes involved in inflammation, and better cognitive performance in healthy aged individuals [46]. However, we did not see a significant improvement in measures of neuroinflammation or behavioral deficits induced by the overexpression of the $(\mathrm{GGGGCC})_{66}$ repeat when Tmem106b levels were reduced. In fact, (GGGGCC) 66 -injected Tmem106b knockout mice showed more severe
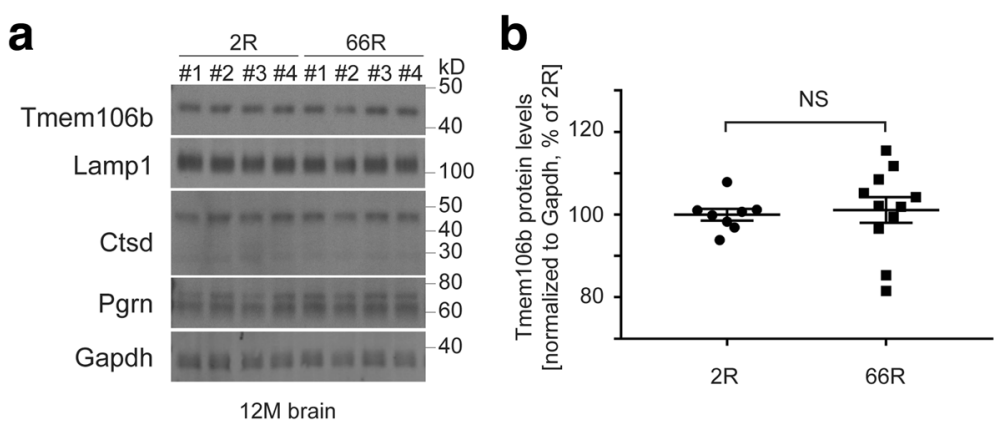

Fig. 5 (GGGGCC) (G6 $_{6}$ repeat expansion overexpression does not alter Tmem106b protein levels in mouse brain. (a) Western blot of brain tissue obtained from 2R- or 66R-injected wild-type mice using antibodies against various lysosomal proteins. Gapdh was used as a loading control. (b) Quantification of Tmem106b protein levels by Western blot as depicted in panel a. The graph represents the mean \pm S.E.M. by Student's $t$ test ( $n=8$ for $2 \mathrm{R} ; \mathrm{n}=12$ for $66 \mathrm{R}$ ); NS, not significant 

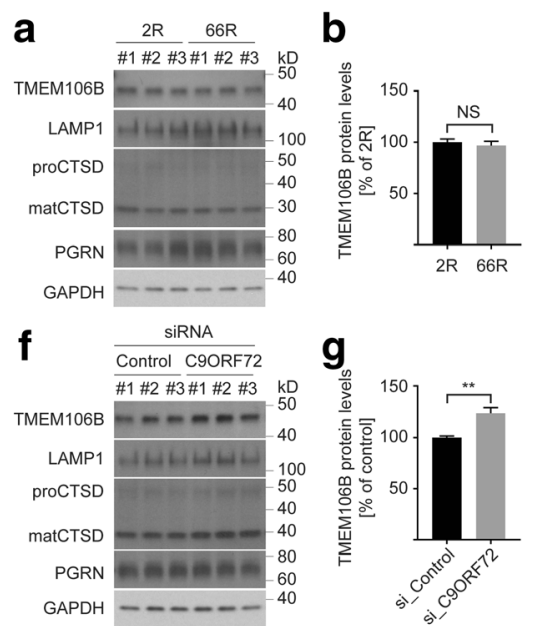

h
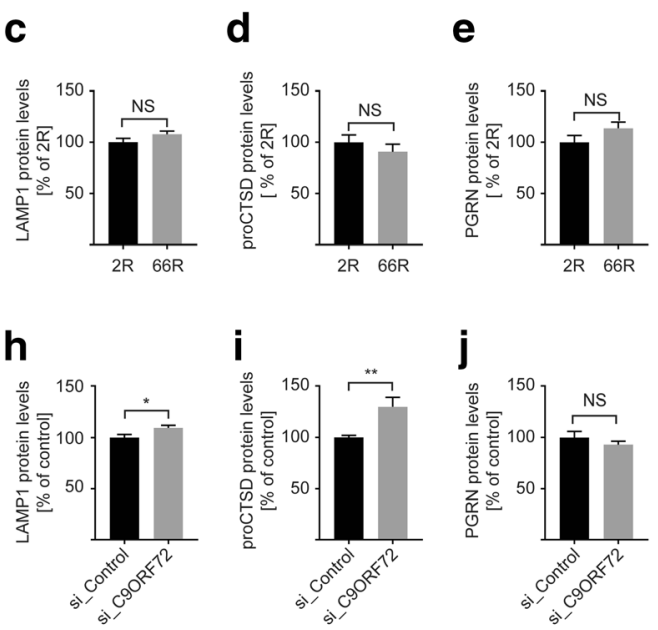

Fig. 6 The effect of (GGGGCC) 66 overexpression or C9ORF72 knockdown on TMEM106B protein levels in HeLa cells. a Western blot of HeLa cells transfected with either 2R or 66R pAAV. b-e Protein quantification of TMEM106B (b), LAMP1 (c), CTSD (pro-form, mature form has similar results as the pro-form) (d), and PGRN (e) in cells transfected as described in panel (a). f Western blot of HeLa cells transfected with either control siRNA or siRNA against C9ORF72 (g-j), Protein quantification of TMEM106B (g), LAMP1 (h), CTSD (i), and PGRN (j) in cells transfected as described in panel f. GAPDH was used as a loading control. Graphs represent the mean \pm S.E.M. by Student's t-test ( $n=6$ for all groups). NS, not significant; ${ }^{*} p<0.05,{ }^{* *} p<0.01$

astrogliosis, evidenced by increased Gfap expression, as compared to Tmem106b wild-type or heterozygous mice injected with the expanded repeat. We showed that this was due to increased astrogliosis from Tmem106b loss alone, excluding the possibility that loss of Tmem106b renders mice more sensitive to a C9ORF72 repeat-mediated inflammatory response. Our observation of astrogliosis resulting from loss of Tmem106b alone suggests that Tmem106b plays a unique and potentially necessary role in astrocytes. Tmem106b is a lysosomal resident protein, and loss of Tmem106b has been recently shown to cause lysosomal dysfunctions including lysosomal acidification and trafficking problems [26, 49]. Importantly, dysfunction of lysosomes in multiple diseases, for instance, lysosomal storage disorders has been tightly linked to astroglial activation [42]. Interestingly, activation of the Tmem106b paralog, Tmem106a, was shown to be immunostimulatory in mouse macrophages [15]. As such, our data suggests that TMEM106B might play a novel, reciprocal role in inflammatory modulation. In relation to the neuronal loss, we did observe that partial, but not complete loss of Tmem106b significantly lessened the extent of neuronal loss in the AAV-(GGGGCC) ${ }_{66}$ injected mice, suggesting that, if pursued, partial TMEM106B reduction may be a more viable avenue for future TMEM106B-related therapeutic approaches in FTD.

Tmem106b levels also had no effect on two other key pathological features observed in the (GGGGCC) ${ }_{66}-\mathrm{AAV}$ model: RNA foci and the generation of dipeptide repeat proteins. These data are in line with a previous report that did not find an association between TMEM106B variants and dipeptide repeat pathology in C9ORF72 mutation carriers [16]. Given the strong genetic association of both GRN and C9ORF72 carriers with TMEM106B variants, the lack of association in our Tmem106b model with pathological features that are unique to C9ORF72GGGGCC repeat expansion carriers may not be surprising. Nevertheless, both C9ORF72 and GRN mutation carriers present with TDP-43 pathology at autopsy. Indeed, TMEM106B variants were first discovered as disease modifiers in an FTD cohort comprised of individuals with TDP-43 brain pathology regardless of underlying cause [59]. TMEM106B variants were additionally found to associate with the presence of TDP-43 pathology in other diseases, such as Alzheimer's disease and hippocampal sclerosis [3, 35, 48]. In fact, the protective TMEM106B variants appeared to correspond with lessened TDP-43 aggregate burden in a preliminary study of eight C9ORF72 mutation carriers [58]. Collectively, these findings suggest that TMEM106B protective variants may reduce one's risk of developing TDP-43 proteinopathies; however, despite careful analysis with two independent antibodies, we found that reducing Tmem106b levels in (GGGGCC) ${ }_{66}$-injected mice did not lessen the development of phosphorylated pTdp-43 aggregates in the cortex or hippocampus at 12 months of age.

The inability to ameliorate neuropathological and behavioral deficits through the reduction of Tmem106b in the AAV-(GGGGCC) 66 model requires a careful examination of the approaches employed in this study. First, we modelled the protective TMEM106B human haplotype by reducing $T m e m 106 b$ by approximately 50 
or $100 \%$. This seems appropriate since multiple studies have observed lower TMEM106B mRNA levels or a faster TMEM106B protein degradation associated with the TMEM106B protective haplotype [20, 37, 59]. We cannot, however, exclude that the associated variants affect TMEM106B in an unknown fashion, for example as a result of the p.Thr185Ser variant (rs3173615) which alters the protein coding sequence of TMEM106B and is inherited as part of the protective haplotype [59]. It is also possible that the protective TMEM106B haplotype induces a more subtle decrease in TMEM106B than what we modeled in this study or that the $\mathrm{N}$-terminal TMEM106B fragments, which we detected at low levels in knockout animals, may have retained some partial TMEM106B function. Second, we modelled the C9ORF72-associated repeat expansion through the overexpression of (GGGGCC) 66 by AAV. This approach importantly results in pTdp-43-positive inclusions as early as 6 months of age [12]; however, this model may have been too aggressive to reverse the neurodegenerative, neuropathological, and behavioral phenotypes in these mice at 12 months of age. More importantly, our approach only recapitulated the RNA and protein toxic gain-of-function mechanisms associated with the repeat sequence and failed to model the reduction in C9ORF72 transcripts which is now considered and integral part of C9ORF72 disease pathogenesis $[1,17,45,56]$. Indeed, endogenous C9orf72 levels were unchanged in our 66R mice at 12 months of age.

TMEM106B is a type II lysosomal membrane protein with currently unknown function. Increases in TMEM106B levels have been found to be cytotoxic and are associated with increases in lysosomal size and reduced lysosomal acidification, leading to the disruption of endolysosomaland autophagic-lysosomal degradation [38]. Recent work undeniably links PGRN to lysosomal biology $[24,31,64,65]$ and, as such, it may not have been surprising that Tmem106b loss reversed some of the Grn knockout-mediated lysosomal enzyme dysregulation [26]. This prompts the question of whether Tmem106b reduction might only confer protection in disease models that portray abnormal lysosomal biology. While lysosomal dysfunction has been implicated in C9ORF72-related pathogenesis, much of the evidence to support this comes from studies investigating the function of the C9ORF72 protein itself and not the $(\text { GGGGCC })_{n}$ repeat expansions [2, 8, 27, 40, 52, 55]. The C9ORF72 protein sequence contains DENN-like domains, making it a part of the DENN protein superfamily which is known to be involved in regulating membrane trafficking and autophagy [32, 63]. Genetic and cell biology studies have shown that C9ORF72 interacts with other DENN domain-containing proteins linked to mTORC1 signaling, whose activity is closely tied to lysosomal function $[2,51,55,62]$. Specifically, loss of C9ORF72, as seen in human patients carrying C9ORF72 repeat expansions, causes impaired mTORC1 signaling and abnormal lysosome morphology indicative of dysfunction $[2,57]$. Thus, it is conceivable that the effect of the protective TMEM106B haplotype in C9ORF72 expansion carriers is to counteract lysosomal dysfunction that results from the loss of C9ORF72 expression. In support of this hypothesis, we showed that reducing C9ORF72 levels in human cell lines significantly increased levels of various lysosomal proteins, including TMEM106B, which is thought to signify lysosomal dysfunction. These types of lysosomal changes were not observed by overexpression of (GGGGCC) $)_{66}$ in cell culture, nor were these changes observed in our AAV-(GGGGCC) ${ }_{66}$ mouse model.

\section{Conclusions}

In summary, we show that reducing the levels of Tmem106b in a mouse model mimicking the toxic gain-of-functions associated with the C9ORF72 (GGGG $\mathrm{CC})_{\mathrm{n}}$ repeat expansions is unable to ameliorate key pathological features seen in FTD patients, including pTdp-43 pathology. We further provide support for the growing body of evidence linking the loss of C9ORF72 expression to the pathobiology of C9ORF72, in this case through the induction of lysosomal dysfunction. As such, it will be critically important that further examination of the effects of Tmem106b reduction on C9ORF72 pathobiology be studied in models that include reduction of C9ORF72.

\section{Additional file}

Additional file 1: Figures S1 through S10. Figure S1. Transcript expression of Tmem106b in Tmem106b deficiency mice at different ages. Figure S2. Tmem106b reduction does not alter the expression of its family members. Figure S3. Tmem 106b immunoreactivity in mice with Tmem106b gene interruption using an additional antibody. Figure S4. The body weight of $2 R$ and 66R injected mouse. Figure S5. Tmem106b reduction alone induces astrogliosis. Figure S6. Heterozygous loss of Tmem106b partially rescues 66R injection-induced neuronal loss. Figure S7. pTdp-43 immunoreactivity in $2 \mathrm{R}$ and $66 \mathrm{R}$ injected mouse brain. Figure S8. Endogenous C9orf72 protein levels in 2R- and 66R-injected mouse brain. Figure S9. Validation of (GGGGCC) 66 repeat overexpression and C9ORF72 knockdown. Figure S10. The effect of (GGGGCC) 66 overexpression or C9ORF72 knockdown on TMEM106B protein levels in U251 cells. (DOCX $26231 \mathrm{~kb})$

\section{Acknowledgements}

This work is funded in part by a Mayo Clinic Edward C. Kendall Research Fellowship (AN) and a research fellowship from The Bluefield Project to Cure FTD (XZ). Additional funding was obtained by NIH/NINDS grants R35NS097261 (RR), UG3NS0103870 (RR) and P01NS084974 (LP, RR, DWD) and The Bluefield Project to Cure FTD (RR).

\section{Authors' contributions}

RR, AMN and XZ designed the study, oversaw the experiments and drafted the manuscript. JC and AMN injected the AAV virus into Tmem106b mice. $\mathrm{RBP}, \mathrm{TP}, \mathrm{MB}, \mathrm{NF}$, and $\mathrm{BM}$ harvested mouse brains and assisted in

biochemical, gene expression and genetic analysis of mouse tissues. NF and 
TP performed and analyzed the cell culture studies. AK, MB and JF performed the mouse behavioral analyses. MC-C, LR, VP, MEM and DD performed the immunohistochemical analyses of mouse brains. MD-H performed FISH analysis to quantify RNA foci burden and LD and TFG performed quantitative analysis of GP levels. LP, KRJ-W and EP generated the AAV virus and FH provided Tmem106b antibody. All authors read and a pproved the final manuscript.

\section{Ethics approval}

All animal studies were approved by the Mayo Clinic Institutional Animal Care and Use Committee.

\section{Competing interests}

The authors declare that they have no competing interests.

\section{Publisher's Note}

Springer Nature remains neutral with regard to jurisdictional claims in published maps and institutional affiliations.

\section{Author details}

'Department of Neuroscience, Mayo Clinic Jacksonville, 4500 San Pablo Road, Jacksonville, FL 32224, USA. ²Department of Molecular Biology and Genetics, Weill Institute for Cell and Molecular Biology, Cornell University, 345 Weill Hall, Ithaca, NY 14853, USA.

\section{Received: 10 May 2018 Accepted: 11 May 2018}

\section{Published online: 31 May 2018}

\section{References}

1. Amick J, Ferguson SM (2017) C9orf72: at the intersection of lysosome cell biology and neurodegenerative disease. Traffic 18:267-276. https://doi.org/ 10.1111/tra.12477

2. Amick J, Roczniak-Ferguson A, Ferguson SM (2016) C9orf72 binds SMCR8, localizes to lysosomes, and regulates mTORC1 signaling. Mol Biol Cell 27: 3040-3051. https://doi.org/10.1091/mbc.E16-01-0003

3. Aoki N, Murray ME, Ogaki K, Fujioka S, Rutherford NJ, Rademakers R, Ross OA, Dickson DW (2015) Hippocampal sclerosis in Lewy body disease is a TDP-43 proteinopathy similar to FTLD-TDP type a. Acta Neuropathol 129: 53-64. https://doi.org/10.1007/s00401-014-1358-z

4. Arai T, Hasegawa M, Akiyama H, Ikeda K, Nonaka T, Mori H, Mann D, Tsuchiya K, Yoshida M, Hashizume Y et al (2006) TDP-43 is a component of ubiquitin-positive tau-negative inclusions in frontotemporal lobar degeneration and amyotrophic lateral sclerosis. Biochem Biophys Res Commun 351:602-611. https://doi.org/10.1016/j.bbrc.2006.10.093

5. Ash PE, Bieniek KF, Gendron TF, Caulfield T, Lin WL, Dejesus-Hernandez M, van Blitterswijk MM, Jansen-West K, Paul JW 3rd, Rademakers R et al (2013) Unconventional translation of C9ORF72 GGGGCC expansion generates insoluble polypeptides specific to C9FTD/ALS. Neuron 77:639-646. https:// doi.org/10.1016/j.neuron.2013.02.004

6. Baker M, Mackenzie IR, Pickering-Brown SM, Gass J, Rademakers R, Lindholm C, Snowden J, Adamson J, Sadovnick AD, Rollinson S et al (2006) Mutations in progranulin cause tau-negative frontotemporal dementia linked to chromosome 17. Nature 442:916-919. https://doi.org/10.1038/nature05016

7. Brady OA, Zheng Y, Murphy K, Huang M, Hu F (2012) The frontotemporal lobar degeneration risk factor, TMEM106B, regulates lysosomal morphology and function. Hum Mol Genet. https://doi.org/10.1093/hmg/dds475

8. Burberry A, Suzuki N, Wang JY, Moccia R, Mordes DA, Stewart MH, SuzukiUematsu S, Ghosh S, Singh A, Merkle FT et al (2016) Loss-of-function mutations in the C9ORF72 mouse ortholog cause fatal autoimmune disease. Sci Transl Med 8: 347ra393 Doi https://doi.org/10.1126/scitranslmed.aaf6038

9. Cecconi F, Meyer BI (2000) Gene trap: a way to identify novel genes and unravel their biological function. FEBS Lett 480:63-71

10. Chakrabarty P, Rosario A, Cruz P, Siemienski Z, Ceballos-Diaz C, Crosby K, Jansen K, Borchelt DR, Kim JY, Jankowsky JL et al (2013) Capsid serotype and timing of injection determines AAV transduction in the neonatal mice brain. PLoS One 8:e67680. https://doi.org/10.1371/journal.pone.0067680

11. Chen-Plotkin AS, Unger TL, Gallagher MD, Bill E, Kwong LK, Volpicelli-Daley L, Busch Jl, Akle S, Grossman M, Van Deerlin V et al (2012) TMEM106B, the risk gene for frontotemporal dementia, is regulated by the microRNA-132/ 212 cluster and affects progranulin pathways. J Neurosci 32:11213-11227. https://doi.org/10.1523/JNEUROSCI.0521-12.2012
12. Chew J, Gendron TF, Prudencio M, Sasaguri H, Zhang YJ, Castanedes-Casey M, Lee CW, Jansen-West K, Kurti A, Murray ME et al (2015)

Neurodegeneration. C9ORF72 repeat expansions in mice cause TDP-43 pathology, neuronal loss, and behavioral deficits. Science 348:1151-1154. https://doi.org/10.1126/science.aaa9344

13. Cruchaga C, Graff C, Chiang HH, Wang J, Hinrichs AL, Spiegel N, Bertelsen S, Mayo K, Norton JB, Morris JC et al (2011) Association of TMEM106B gene polymorphism with age at onset in Granulin mutation carriers and plasma Granulin protein levels. Arch Neurol. https:/doi.org/10.1001/archneurol.2010.350

14. Cruts M, Gijselinck I, van der Zee J, Engelborghs S, Wils H, Pirici D, Rademakers R, Vandenberghe R, Dermaut B, Martin JJ et al (2006) Null mutations in progranulin cause ubiquitin-positive frontotemporal dementia linked to chromosome 17q21. Nature 442:920-924. https://doi.org/10.1038/nature05017

15. Dai H, Xu D, Su J, Jang J, Chen Y (2015) Transmembrane protein 106a activates mouse peritoneal macrophages via the MAPK and NF-kappaB signaling pathways. Sci Rep 5:12461. https://doi.org/10.1038/srep12461

16. Davidson YS, Barker H, Robinson AC, Thompson JC, Harris J, Troakes C, Smith B, Al-Saraj S, Shaw C, Rollinson S et al (2014) Brain distribution of dipeptide repeat proteins in frontotemporal lobar degeneration and motor neurone disease associated with expansions in C9ORF72. Acta Neuropathol Commun 2:70. https://doi.org/10.1186/2051-5960-2-70

17. DeJesus-Hernandez M, Mackenzie IR, Boeve BF, Boxer AL, Baker M, Rutherford NJ, Nicholson AM, Finch NA, Flynn H, Adamson J et al (2011) Expanded GGGGCC hexanucleotide repeat in noncoding region of C9ORF72 causes chromosome 9p-linked FTD and ALS. Neuron 72:245-256. https://doi.org/10.1016/j.neuron.2011.09.011

18. Deming Y, Cruchaga C (2014) TMEM106B: a strong FTLD disease modifier. Acta Neuropathol 127:419-422. https://doi.org/10.1007/s00401-014-1249-3

19. Finch N, Carrasquillo MM, Baker M, Rutherford NJ, Coppola G, DejesusHernandez M, Crook R, Hunter T, Ghidoni R, Benussi L et al (2011) TMEM $106 \mathrm{~B}$ regulates progranulin levels and the penetrance of FTLD in GRN mutation carriers. Neurology 76:467-474. https://doi.org/10.1212/WNL. Ob013e31820a0e3b

20. Gallagher MD, Posavi M, Huang P, Unger TL, Berlyand Y, Gruenewald AL, Chesi A, Manduchi E, Wells AD, Grant SF et al (2017a) A dementiaassociated risk variant near TMEM106B alters chromatin architecture and gene expression. Am J Hum Genet 101:643-663. https://doi.org/10.1016/j. ajhg.2017.09.004

21. Gallagher MD, Suh E, Grossman M, Elman L, McCluskey L, Van Swieten JC, Al-Sarraj S, Neumann M, Gelpi E, Ghetti B et al (2014) TMEM106B is a genetic modifier of frontotemporal lobar degeneration with C9orf72 hexanucleotide repeat expansions. Acta Neuropathol 127:407-418. https:// doi.org/10.1007/s00401-013-1239-x

22. Gendron TF, Bieniek KF, Zhang YJ, Jansen-West K, Ash PE, Caulfield T, Daughrity L, Dunmore JH, Castanedes-Casey M, Chew J et al (2013) Antisense transcripts of the expanded C9ORF72 hexanucleotide repeat form nuclear RNA foci and undergo repeat-associated non-ATG translation in C9FTD/ALS. Acta Neuropathol 126:829-844. https://doi.org/10.1007/s00401-013-1192-8

23. Goldman JS, Farmer JM, Wood EM, Johnson JK, Boxer A, Neuhaus J, LomenHoerth C, Wilhelmsen KC, Lee VM, Grossman M et al (2005) Comparison of family histories in FTLD subtypes and related tauopathies. Neurology 65 1817-1819. https://doi.org/10.1212/01.wnl.0000187068.92184.63

24. Holler CJ, Taylor G, Deng Q, Kukar T (2017) Intracellular proteolysis of Progranulin generates stable, lysosomal Granulins that are Haploinsufficient in patients with frontotemporal dementia caused by GRN mutations. eNeuro 4. https://doi.org/10.1523/ENEURO.0100-17.2017

25. Kim JY, Grunke SD, Levites Y, Golde TE, Jankowsky JL (2014) Intracerebroventricular viral injection of the neonatal mouse brain for persistent and widespread neuronal transduction. J Vis Exp 51863. https:// doi.org/10.3791/51863

26. Klein ZA, Takahashi H, Ma M, Stagi M, Zhou M, Lam TT, Strittmatter SM (2017) Loss of TMEM106B ameliorates lysosomal and frontotemporal dementia-related phenotypes in Progranulin-deficient mice. Neuron 95(281296):e286. https://doi.org/10.1016/j.neuron.2017.06.026

27. Koppers M, Blokhuis AM, Westeneng HJ, Terpstra ML, Zundel CA, Vieira de Sa R, Schellevis RD, Waite AJ, Blake DJ, Veldink JH et al (2015) C9orf72 ablation in mice does not cause motor neuron degeneration or motor deficits. Ann Neurol 78:426-438. https://doi.org/10.1002/ana.24453

28. Lagier-Tourenne C, Baughn M, Rigo F, Sun S, Liu P, Li HR, Jiang J, Watt AT, Chun S, Katz M et al (2013) Targeted degradation of sense and antisense C9orf72 RNA foci as therapy for ALS and frontotemporal degeneration. Proc 
Natl Acad Sci U S A 110:E4530-E4539. https://doi.org/10.1073/pnas. 1318835110

29. Lang CM, Fellerer K, Schwenk BM, Kuhn PH, Kremmer E, Edbauer D, Capell A, Haass C (2012) Membrane orientation and subcellular localization of transmembrane protein 106B (TMEM106B), a major risk factor for frontotemporal lobar degeneration. J Biol Chem 287:19355-19365. https:// doi.org/10.1074/jbc.M112.365098

30. Lattante S, Le Ber I, Galimberti D, Serpente M, Rivaud-Pechoux S, Camuzat A, Clot F, Fenoglio C, Scarpini E, Brice A et al (2014) Defining the association of TMEM106B variants among frontotemporal lobar degeneration patients with GRN mutations and C9orf72 repeat expansions. Neurobiol Aging 35(2658):e2651-e2655. https://doi.org/10.1016/j.neurobiolaging.2014.06.023

31. Lee CW, Stankowski JN, Chew J, Cook CN, Lam YW, Almeida S, Carlomagno Y, Lau KF, Prudencio M, Gao FB et al (2017) The lysosomal protein cathepsin $\mathrm{L}$ is a progranulin protease. Mol Neurodegener 12:55. https://doi.org/10. 1186/s13024-017-0196-6

32. Levine TP, Daniels RD, Gatta AT, Wong LH, Hayes MJ (2013) The product of C9orf72, a gene strongly implicated in neurodegeneration, is structurally related to DENN Rab-GEFs. Bioinformatics 29:499-503. https://doi.org/10, 1093/bioinformatics/bts725

33. Mori K, Arzberger T, Grasser FA, Gijselinck I, May S, Rentzsch K, Weng SM, Schludi MH, van der Zee J, Cruts M et al (2013a) Bidirectional transcripts of the expanded C9orf72 hexanucleotide repeat are translated into aggregating dipeptide repeat proteins. Acta Neuropathol 126:881-893. https://doi.org/10.1007/s00401-013-1189-3

34. Mori K, Weng SM, Arzberger T, May S, Rentzsch K, Kremmer E, Schmid B, Kretzschmar HA, Cruts M, Van Broeckhoven C et al (2013b) The C9orf72 GGGGCC repeat is translated into aggregating dipeptide-repeat proteins in FTLD/ALS. Science 339:1335-1338. https://doi.org/10.1126/science.1232927

35. Murray ME, Cannon A, Graff-Radford NR, Liesinger AM, Rutherford NJ, Ross OA, Duara R, Carrasquillo MM, Rademakers R, Dickson DW (2014) Differential clinicopathologic and genetic features of late-onset amnestic dementias. Acta Neuropathol 128:411-421. https://doi.org/10.1007/s00401-014-1302-2

36. Neumann M, Sampathu DM, Kwong LK, Truax AC, Micsenyi MC, Chou TT, Bruce J, Schuck T, Grossman M, Clark CM et al (2006) Ubiquitinated TDP-43 in frontotemporal lobar degeneration and amyotrophic lateral sclerosis. Science 314:130-133

37. Nicholson AM, Finch NA, Wojtas A, Baker MC, Perkerson RB 3rd, Castanedes-Casey M, Rousseau L, Benussi L, Binetti G, Ghidoni R et al (2013) TMEM106B p.T185S regulates TMEM106B protein levels: implications for frontotemporal dementia. J Neurochem 126:781-791. https://doi.org/10.1111/jnc.12329

38. Nicholson AM, Rademakers $R$ (2016) What we know about TMEM106B in neurodegeneration. Acta Neuropathol 132:639-651. https://doi.org/10.1007/ s00401-016-1610-9

39. O'Rourke JG, Bogdanik L, Muhammad A, Gendron TF, Kim KJ, Austin A, Cady J, Liu EY, Zarrow J, Grant S et al (2015) C9orf72 BAC transgenic mice display typical pathologic features of ALS/FTD. Neuron 88:892-901. https://doi.org/ 10.1016/j.neuron.2015.10.027

40. O'Rourke JG, Bogdanik L, Yanez A, Lall D, Wolf AJ, Muhammad AK, Ho R, Carmona S, Vit JP, Zarrow J et al (2016) C9orf72 is required for proper macrophage and microglial function in mice. Science 351:1324-1329. https://doi.org/10.1126/science.aaf1064

41. Peters OM, Cabrera GT, Tran H, Gendron TF, McKeon JE, Metterville J, Weiss A, Wightman N, Salameh J, Kim J et al (2015) Human C9ORF72 Hexanucleotide expansion reproduces RNA foci and dipeptide repeat proteins but not neurodegeneration in BAC transgenic mice. Neuron 88: 902-909. https://doi.org/10.1016/.j.neuron.2015.11.018

42. Platt FM, Boland B, van der Spoel AC (2012) The cell biology of disease: lysosomal storage disorders: the cellular impact of lysosomal dysfunction. Cell Biol 199:723-734. https://doi.org/10.1083/jcb.201208152

43. Rascovsky K, Hodges JR, Knopman D, Mendez MF, Kramer JH, Neuhaus J, van Swieten JC, Seelaar H, Dopper EG, Onyike CU et al (2011) Sensitivity of revised diagnostic criteria for the behavioural variant of frontotemporal dementia. Brain 134:2456-2477. https://doi.org/10.1093/brain/awr179

44. Ratnavalli E, Brayne C, Dawson K, Hodges JR (2002) The prevalence of frontotemporal dementia. Neurology 58:1615-1621

45. Renton AE, Majounie E, Waite A, Simon-Sanchez J, Rollinson S, Gibbs JR, Schymick JC, Laaksovirta H, van Swieten JC, Myllykangas L et al (2011) A hexanucleotide repeat expansion in C9ORF72 is the cause of chromosome 9p21linked ALS-FTD. Neuron 72:257-268. https://doi.org/10.1016/..neuron.2011.09.010
46. Rhinn $\mathrm{H}$, Abeliovich A (2017) Differential aging analysis in human cerebral cortex identifies variants in TMEM106B and GRN that regulate aging phenotypes. Cell Syst 4(404-415):e405. https://doi.org/10.1016/j.cels.2017.02.009

47. Rosso SM, Donker Kaat L, Baks T, Joosse M, de Koning I, Pijnenburg Y, de Jong D, Dooijes D, Kamphorst W, Ravid R et al (2003) Frontotemporal dementia in the Netherlands: patient characteristics and prevalence estimates from a populationbased study. Brain 126:2016-2022. https://doi.org/10.1093/brain/awg204

48. Rutherford NJ, Carrasquillo MM, Li M, Bisceglio G, Menke J, Josephs KA, Parisi JE, Petersen RC, Graff-Radford NR, Younkin SG et al (2012) TMEM106B risk variant is implicated in the pathologic presentation of Alzheimer disease. Neurology 79:717-718. https://doi.org/10.1212/WNL. ob013e318264e3ac

49. Schwenk BM, Lang CM, Hogl S, Tahirovic S, Orozco D, Rentzsch K, Lichtenthaler SF, Hoogenraad CC, Capell A, Haass C et al (2014a) The FTLD risk factor TMEM106B and MAP6 control dendritic trafficking of lysosomes. EMBO J 33:450-467. https://doi.org/10.1002/embj.201385857

50. Schwenk BM, Lang CM, Hogl S, Tahirovic S, Orozco D, Rentzsch K, Lichtenthaler SF, Hoogenraad CC, Capell A, Haass C et al (2014b) The FTLD risk factor TMEM106B and MAP6 control dendritic trafficking of lysosomes. Embo J. https://doi.org/10.1002/embj.201385857

51. Sellier C, Campanari ML, Julie Corbier C, Gaucherot A, Kolb-Cheynel I, OuladAbdelghani M, Ruffenach F, Page A, Ciura S, Kabashi E et al (2016) Loss of C9ORF72 impairs autophagy and synergizes with polyQ Ataxin-2 to induce motor neuron dysfunction and cell death. EMBO J 35:1276-1297. https:// doi.org/10.15252/embj.201593350

52. Shi Y, Lin S, Staats KA, Li Y, Chang WH, Hung ST, Hendricks E, Linares GR, Wang Y, Son EY et al (2018) Haploinsufficiency leads to neurodegeneration in C9ORF72 ALS/FTD human induced motor neurons. Nat Med 24:313-325. https://doi.org/10.1038/nm.4490

53. Stagi M, Klein ZA, Gould TJ, Bewersdorf J, Strittmatter SM (2014) Lysosome size, motility and stress response regulated by fronto-temporal dementia modifier TMEM106B. Mol Cell Neurosci 61:226-240. https://doi.org/10.1016/j. men.2014.07.006

54. Su Z, Zhang Y, Gendron TF, Bauer PO, Chew J, Yang WY, Fostvedt E, JansenWest K, Belzil W, Desaro P et al (2014) Discovery of a biomarker and lead small molecules to target $\mathrm{r}(\mathrm{GGGGCC})$-associated defects in C9FTD/ALS. Neuron 83:1043-1050. https://doi.org/10.1016/j.neuron.2014.07.041

55. Sullivan PM, Zhou X, Robins AM, Paushter DH, Kim D, Smolka MB, Hu F (2016) The ALS/FTLD associated protein C9orf72 associates with SMCR8 and WDR41 to regulate the autophagy-lysosome pathway. Acta Neuropathol Commun 4:51. https://doi.org/10.1186/s40478-016-0324-5

56. Taylor JP, Brown RH Jr, Cleveland DW (2016) Decoding ALS: from genes to mechanism. Nature 539:197-206. https://doi.org/10.1038/nature20413

57. Ugolino J, Ji YJ, Conchina K, Chu J, Nirujogi RS, Pandey A, Brady NR, Hamacher-Brady A, Wang J (2016) Loss of C9orf72 enhances Autophagic activity via deregulated mTOR and TFEB signaling. PLoS Genet 12:e1006443. https://doi.org/10.1371/journal.pgen.1006443

58. van Blitterswijk M, Mullen B, Nicholson AM, Bieniek KF, Heckman MG, Baker MC, Dejesus-Hernandez M, Finch NA, Brown PH, Murray ME et al (2014) TMEM106B protects C9ORF72 expansion carriers against frontotemporal dementia. Acta Neuropathol. https://doi.org/10.1007/s00401-013-1240-4

59. Van Deerlin VM, Sleiman PM, Martinez-Lage M, Chen-Plotkin A, Wang LS, Graff-Radford NR, Dickson DW, Rademakers R, Boeve BF, Grossman M et al (2010) Common variants at 7p21 are associated with frontotemporal lobar degeneration with TDP-43 inclusions. Nat Genet 42:234-239. https://doi.org/ 10.1038/ng.536

60. van der Zee J, Van Langenhove T, Kleinberger G, Sleegers K, Engelborghs S, Vandenberghe R, Santens P, Van den Broeck M, Joris G, Brys J et al (2011) TMEM106B is associated with frontotemporal lobar degeneration in a clinically diagnosed patient cohort. Brain 134:808-815. https://doi.org/10. 1093/brain/awr007

61. Wood EM, Falcone D, Suh E, Irwin DJ, Chen-Plotkin AS, Lee EB, Xie SX, Van Deerlin VM, Grossman M (2013) Development and validation of pedigree classification criteria for frontotemporal lobar degeneration. JAMA Neurol 70:1411-1417. https://doi.org/10.1001/jamaneurol.2013.3956

62. Yang M, Liang C, Swaminathan K, Herrlinger S, Lai F, Shiekhattar R, Chen JF (2016) A C9ORF72/SMCR8-containing complex regulates ULK1 and plays a dual role in autophagy. Sci Adv 2:e1601167. https://doi.org/ 10.1126/sciadv. 1601167

63. Zhang D, lyer $L M, H e F$, Aravind L (2012) Discovery of novel DENN proteins: implications for the evolution of eukaryotic intracellular membrane 
structures and human disease. Front Genet 3:283. https://doi.org/10.3389/ fgene.2012.00283

64. Zhou X, Paushter DH, Feng T, Pardon CM, Mendoza CS, Hu F (2017a) Regulation of cathepsin D activity by the FTLD protein progranulin. Acta Neuropathol 134:151-153. https://doi.org/10.1007/s00401-017-1719-5

65. Zhou X, Paushter DH, Feng T, Sun L, Reinheckel T, Hu F (2017b) Lysosomal processing of progranulin. Mol Neurodegener 12:62. https://doi.org/10.1186/ s13024-017-0205-9

Ready to submit your research? Choose BMC and benefit from:

- fast, convenient online submission

- thorough peer review by experienced researchers in your field

- rapid publication on acceptance

- support for research data, including large and complex data types

- gold Open Access which fosters wider collaboration and increased citations

- maximum visibility for your research: over $100 \mathrm{M}$ website views per year 